\title{
Monensina sódica e Saccharomyces cerevisiae em dietas para bovinos: fermentação ruminal, digestibilidade dos nutrientes e eficiência de síntese microbiana
}

\author{
Fernanda Fereli ${ }^{1}$, Antonio Ferriani Branco ${ }^{2}$, Clóves Cabreira Jobim² ${ }^{2}$, Sabrina Marcantonio \\ Coneglian $^{3}$, Fernanda Granzotto ${ }^{3}$, Julio Cezar Barreto ${ }^{3}$
}

\author{
${ }^{1}$ Mestranda em Zootecnia - UEM \\ 2 Departamento de Zootecnia - UEM, Av. Colombo, 5790 - CEP: 87020-000 - Maringá, PR. Bolsista CNPq. \\ ${ }^{3}$ Doutorando em Zootecnia - UEM.
}

RESUMO - Avaliaram-se os efeitos do uso de monensina sódica, Saccharomyces cerevisiae e da mistura de ambos na dieta de bovinos sobre o pH e a concentração de amônia no rúmen, a digestibilidade aparente parcial e total dos nutrientes e a síntese de proteína microbiana no rúmen. Foram utilizados quatro bovinos da raça Holandesa Preto e Branco, castrados, com 320 kg de peso vivo, e canulados no rúmen. O delineamento experimental utilizado foi o quadrado latino $4 \times 4$, e os tratamentos consistiram de doses diárias de: 200 mg de monensina sódica (100I); 100 mg monensina sódica + 2,5 g Saccharomyces cerevisiae (50IP); 200 mg de monensina sódica + 5 g Saccharomyces cerevisiae (100IP); e 5 g Saccharomyces cerevisiae (100P), fornecidos diariamente pela cânula ruminal. A dieta contendo 100I promoveu menor digestão intestinal e total da matéria seca (MS), maior digestão intestinal da fibra em detergente neutro (FDN) e do extrato etéreo (EE), maior digestão total da proteína bruta (PB) e do EE e maior coeficiente de digestibilidade aparente ruminal (CDAR) e total (CDAT) da PB. A dieta contendo 100P resultou em menor digestão ruminal da PB, maior digestão ruminal da FDN, maior digestão intestinal da matéria orgânica (MO), da PB e dos carboidratos não-fibrosos (CNF), maior digestão total da matéria orgânica e do extrato etéreo, maior CDAR da FDN, maior coeficiente de digestibilidade intestinal (CDAI) da MO e dos CNF e maior CDAT da MO. A dieta 100P promoveu maior fluxo omasal de nitrogênio bacteriano e maior eficiência microbiana aparente e verdadeira. A dieta com 5 g/dia de Saccharomyces cerevisiae apresentou valor de NDT superior ao das outras dietas. As dietas não diferem quanto ao pH e à concentração de amônia no rúmen.

Palavras-chave: levedura, microrganismos celulolíticos, probióticos, produção microbiana

\section{Sodium monensin and Saccharomyces cerevisiae in cattle diets: ruminal fermentation, nutrient digestibility and microbial synthesis efficiency}

\footnotetext{
ABSTRACT - The study was conducted to evaluate effects of sodium monensin, Saccharomyces cerevisiae and a mixture of both, in cattle diets, on ruminal $\mathrm{pH}$ and ammonia concentration, partial and total nutrient digestibility, and microbial protein synthesis in the rumen. Four Holstein steers weighting $320 \mathrm{~kg}$ and cannulated in the rumen were used. A $4 \times 4$ Latin square experimental design was used and treatments consisted of daily intake of: 200 mg of sodium monensin (100I); $100 \mathrm{mg}$ of sodium monensin $+2.5 \mathrm{~g}$ of Saccharomyces cerevisiae (50IP); $200 \mathrm{mg}$ sodium monensin $+5 \mathrm{~g}$ Saccharomyces cerevisiae (100IP), and 5 g Saccharomyces cerevisiae (100P) supplied daily through the ruminal canula. The diets containing 100I showed lower intestinal and total DM digestion, higher intestinal digestion of neutral detergent fiber (NDF) and ether extract (EE), higher total digestion of crude protein (CP) and ether extract (EE) and higher apparent ruminal and total CP digestibility. The diets containing 100P showed lower ruminal CP digestion, higher ruminal NDF digestion, higher intestinal digestion of OM, CP, and NFC, higher total digestion of OM and EE, higher apparent ruminal NDF digestibility, higher apparent intestinal digestibility of OM and NFC, and higher apparent total digestibility of OM. Regarding microbial protein synthesis, diets with 100P produced higher omasal flow of bacterial nitrogen and higher apparent and true microbial efficiency. The diets that supplied $5 \mathrm{~g} / \mathrm{d}$ Saccharomyces cerevisiae increased TDN compared to the other diets. The treatments do not differ for ruminal $\mathrm{pH}$ and ammonia concentration.
}

Key Words: cellulolytic microorganisms, microbial production, probiotics, yeast 


\section{Introdução}

A utilização de aditivos na alimentação animal é uma das formas de incrementar a produção. A modificação do processo de fermentação ruminal através da dieta visando melhorar o desempenho animal tem sido objeto de muitas pesquisas em diversas espécies de ruminantes.

De acordo com Martin \& Nisbet (1992), até 12\% da energia oriunda da alimentação pode ser convertida em metano que é perdido através da eructação nos ruminantes, assim, muitas pesquisas tem sido conduzidas com o intuito de reduzir essas perda; os antibióticos ionóforos são os aditivos mais estudados e utilizados com esse objetivo.

Oliveira et al. (2005) relatam que a melhoria da eficiência alimentar proporcionada pela monensina sódica é ocasionada pelas mudanças na população microbiana do rúmen e no padrão de fermentação dos alimentos. Adicionada a dietas de ruminantes, a monensina atua sobre o crescimento de bactérias gram-positivas, de modo que os produtos gerados durante o metabolismo das bactérias beneficiadas proporcionam vantagens nutricionais, metabólicas e no desempenho do animal.

No entanto, os antibióticos usados como promotores de crescimento nas rações foram banidos pela União Europeia (UE) desde janeiro de 2006, o que têm contribuído para intensificar a procura por aditivos alternativos. Entre os aditivos alternativos existentes no mercado, destacam-se as culturas de leveduras, que possuem características que atendem às exigências internacionais dos maiores importadores de carne bovina brasileira (Gattas et al., 2008).

De acordo com Wallace (1994), o uso de Saccharomyces cerevisiae e Aspergillus oryzae, ou seus extratos, pode melhorar o ganho de peso e a produção de leite com intensidade semelhante aos ionóforos, em decorrência da resposta ao aumento na ingestão de matéria seca. Entretanto, as respostas são variáveis e dependem da quantidade oferecida e do tipo de dieta. Segundo Kamalamma et al.(1996), o emprego de culturas de leveduras nas dietas de ruminantes pode provocar alterações na razão acetato/propionato e ainda aumentar o fluxo de proteína microbiana para o intestino delgado.

Esta pesquisa foi conduzida para estudar os efeitos do ionóforo (monensina sódica) e/ou probiótico (Saccharomyces cerevisiae) sobre a digestibilidade aparente parcial e total da matéria seca e seus nutrientes (MO, PB, FDN, CNF eEE), a eficiência de síntese microbiana, e o pH e a concentração de amônia no rúmen de bovinos.

\section{Material e Métodos}

O experimento foi realizado no setor de Avaliação de Alimentos para animais Ruminantes da Fazenda Experimental de Iguatemi (FEI), localizada no distrito de Iguatemi no período de março a junho de 2005 . As análises químicas foram feitas no Laboratório de Análises de Alimentos e Nutrição Animal (LANA) do departamento de Zootecnia, pertencentes à Universidade Estadual de Maringá. Foram utilizados quatro bovinos machos, castrados, da raça Holandesa Preto-e-Branco, com aproximadamente 320 kg de peso vivo médio, portando cânula ruminal.

Os animais foram mantidos em um barracão de alvenaria, totalmente coberto, em baias individuais $\left(8,75 \mathrm{~m}^{2}\right)$, com piso de concreto, e alimentados duas vezes ao dia, pela manhã (8 h) e à tarde (16 h). As baias continham comedouro individual de polietileno e bebedouro automático que servia a duas baias. As baias e os bebedouros eram lavados diariamente para assegurar ambiente higiênico e fornecimento de água de boa qualidade.

Os animais eram pesados no início de cada período experimental, com o objetivo de ajustar o consumo de matéria seca. Cada período experimental teve duração de 21 dias, sendo 16 dias de adaptação e 5 dias para coleta de amostras (alimentos, sobras, líquido omasal, fezes, líquido ruminal e conteúdo ruminal), realizadas no período entre o $17 \underline{0}$ e o $21^{\circ}$ dia.

As rações foram formuladas para conter $14 \%$ de proteína bruta (PB) e 75\% de nutrientes digestíveis totais (NDT) com base na matéria seca (MS), em uma relação de $30 \%$ de volumoso e $70 \%$ de concentrado (Tabela 1 ).

Os tratamentos consistiram em fornecer fontes comerciais de monensina e/ou probiótico (Saccharomyces cerevisiae, Biosaf ${ }^{\circledR}$, SafAgri) da seguinte forma: 1) $200 \mathrm{mg}$ de monensina sódica (100I); 2) 100 mg monensina + 2,5 g de Saccharomyces cerevisiae (50IP); 3) $200 \mathrm{mg}$ de

Tabela 1 - Composição percentual e química das dietas experimentais

\begin{tabular}{lc}
\hline & Dieta experimental \\
\hline Alimento & $\%$ na MS \\
Silagem de milho & 30,44 \\
Milho moído & 61,21 \\
Farelo de soja & 5,08 \\
Ureia & 1,31 \\
Sal mineral & 1,96 \\
Nutriente (\%) & \\
Nutrientes digestíveis totais & 75,5 \\
Proteína bruta & 14,3 \\
Cálcio & 0,56 \\
Fósforo & 0,31 \\
\hline
\end{tabular}


monensina +5 g Saccharomyces cerevisiae (100IP); e 4) $5 \mathrm{~g}$ Saccharomyces cerevisiae (100P). O produto utilizado como probiótico continha cepas vivas e viáveis de leveduras da espécie Saccharomyces cerevisiae, contendo 10 bilhões de unidades formadoras de colônias/grama do produto (ufc/g). O ionóforo e o probiótico foram fornecidos via cânula ruminal, toda manhã, às $8 \mathrm{~h} 30$.

Como indicador externo, para determinação do fluxo da digesta omasal e da produção fecal, foram colocados diariamente no rúmen embrulhos de papel contendo $10 \mathrm{~g}$ de óxido de cromo, a partir do 70 dia de cada período experimental.

Foram coletadas amostras de digesta omasal ( $500 \mathrm{~mL}$ ) e de fezes ( $50 \mathrm{~g}$ ) diretamente do reto, para determinação da digestibilidade parcial e total da matéria seca (MS), matéria orgânica (MO), proteína bruta (PB), fibra em detergente neutro (FDN), extrato etéreo (EE) e carboidratos não-fibrosos (CNF), de acordo com Coelho da Silva \& Leão (1979). Para a coleta das amostras de digesta omasal, foi utilizado um conjunto de dispositivos composto de um recipiente, um tubo coletor e uma bomba a vácuo, conforme técnica descrita por Leão (2004). As amostras de digesta omasal e de fezes foram acondicionadas em sacos plásticos devidamente etiquetados e congeladas $\left(-20^{\circ} \mathrm{C}\right)$ para posterior processamento e análises. As amostras de digesta omasal e de fezes foram coletadas por um período total de quatro dias, em diferentes horários. No primeiro dia, a coleta foi realizada às $8 \mathrm{~h}$ e, nos dias subsequentes a coleta foi realizada com avanço de quatro horas para cada dia, de modo que, no último dia, foi realizada às $20 \mathrm{~h}$, totalizando quatro amostras de digesta omasal e quatro amostras de fezes por animal/tratamento/período.

As amostras de digesta omasal e de fezes foram secas em estufa com circulação forçada de ar a $55{ }^{\circ} \mathrm{C}$, por 96 horas. Depois, foram processadas individualmente em moinhos de faca, utilizando peneira com crivo de $1 \mathrm{~mm}$, e misturadas em quantidades iguais, com base no peso seco, para formar amostras compostas de digesta omasal e fezes por animal/tratamento/período.

As sobras de alimento nos comedouros foram recolhidas diariamente e pesadas, amostradas no período de coleta e congeladas para posteriores análises. As amostras do concentrado e da silagem foram realizadas semanalmente e homogeneizadas em amostras compostas para todo o período experimental. As amostras de silagem e sobras passaram pelo mesmo procedimento descrito anteriormente para o preparo das amostras de digesta omasal e de fezes.

As amostras dos alimentos utilizados nas dietas experimentais, das sobras no cocho, de digesta omasal e de fezes foram analisadas quanto aos teores de MS, MO,
PB e EE segundo o AOAC (1990) e FDN segundo Van Soest et al. (1991). A concentração de cromo nas amostras de líquido omasal e de fezes foi determinada por espectrofotometria de absorção atômica, conforme técnica descrita por Williams et al. (1962), e usada juntamente com a concentração de nutrientes para determinar o fluxo de nutrientes para o omaso e nas fezes.

Os carboidratos não-fibrosos foram calculados pela seguinte equação (Sniffen et al., 1992):

$$
\mathrm{CNF}=100-(\% \mathrm{FDN}+\% \mathrm{~PB}+\% \mathrm{EE}+\% \text { cinzas })
$$

Os nutrientes digestíveis totais das dietas foram calculados pela seguinte equação (Sniffen et al., 1992):

$\mathrm{NDT}=\mathrm{PD}+\mathrm{FDND}+(\mathrm{EED} \times 2,25)+\mathrm{CNFD}$, em que: $\mathrm{PD}=$ proteína digestível, $\mathrm{FDND}=$ fibra em detergente neutro digestível, EED = extrato etéreo digestível, CNFD = carboidratos não-fibrosos digestíveis.

Para determinação do pH e da concentração de amônia no líquido ruminal, foram coletados aproximadamente 100 mL de líquido ruminal no $20^{\circ}$ dia, via cânula ruminal, nos tempos 0; 2; 4; 6 e 8 horas, em cada período experimental. O tempo zero corresponde à amostra colhida imediatamente antes da primeira refeição e o tempo oito, imediatamente antes do fornecimento da segunda refeição (16h).

A cada coleta de líquido ruminal, era medido o $\mathrm{pH}$ da amostra e retirada uma alíquota de $50 \mathrm{~mL}$, que era acidificada com $1 \mathrm{~mL}$ de ácido sulfúrico (1:1) e armazenada em freezer a $-20{ }^{\circ} \mathrm{C}$ para posterior análise de amônia. A dosagem de amônia nas amostras de líquido ruminal foi determinada pela técnica de Ferner (1965), modificada por Vieira (1980).

No último dia de cada período, foi coletada amostra de $1,5 \mathrm{~kg}$ de conteúdo ruminal, para determinação da eficiência de síntese microbiana, e a ela foram adicionados $500 \mathrm{~mL}$ de solução salina $0,9 \%(\mathrm{NaCl})$. A mistura foi homogeneizada em liquidificador, coada em fralda de algodão dobrada quatro vezes e o filtrado, armazenado a $-20{ }^{\circ} \mathrm{C} \mathrm{e}$ analisado de acordo com descrição de Cecava et al. (1990).

A concentração de purinas nas bactérias do rúmen e na digesta omasal foi determinada pelo procedimento descrito por Ushida et al. (1985), com algumas modificações propostas por Bohnert et al. (1998), que são: 1) 15 minutos após o início da primeira incubação, os tubos foram retirados do banho-maria e agitados, voltando para o banho-maria para terminar o período de incubação restante; 2 ) a segunda incubação foi aumentada para 30 minutos; 3) o pélete foi lavado com $10 \mathrm{~mL}$ de $0,005 \mathrm{~N}$ $\mathrm{H}_{2} \mathrm{SO}_{4} / 0,005 \mathrm{M} \mathrm{AgNO}_{3}$; 4) a incubação final foi aumentada para 45 minutos. O fluxo total de nitrogênio microbiano para o duodeno (g/dia) foi estimado pela divisão da razão nitrogênio:purinas bactéria pela razão nitrogênio:purinas 
digesta omasal e multiplicando esse quociente pelo fluxo total individual de nitrogênio.

A eficiência de síntese microbiana também foi expressa em g de $\mathrm{N}$ microbiano/kg de matéria orgânica (MO) verdadeira fermentada no rúmen, que, por sua vez, foi calculada pela equação = ingestão de $\mathrm{MO}(\mathrm{g} / \mathrm{dia})-[\mathrm{MO}$ duodenal (g/dia) - MO microbiana (g/dia)].

$\mathrm{O}$ experimento foi conduzido em delineamento experimental quadrado latino $4 \times 4$ e os dados foram interpretados por análise de variância, adotando-se 5\% de probabilidade, pelo procedimento GLM do SAS (2001).

O modelo matemático utilizado para a análise de variância foi:

$$
\mathrm{Y}_{\mathrm{ijk}}=\mu+\mathrm{A}_{\mathrm{i}}+\mathrm{P}_{\mathrm{j}}+\mathrm{T}_{\mathrm{k}}+\mathrm{e}_{\mathrm{ijk}}
$$

em que: $\mu=$ média dos tratamentos; $A_{i}=$ efeito do animal $i$, variando de 1 a $4 ; \mathrm{P}_{\mathrm{j}}=$ efeito do período $\mathrm{j}$, variando de $1 \mathrm{a}$ $4 ; \mathrm{T}_{\mathrm{k}}=$ efeito do tratamento $\mathrm{k}$, variando de $1 \mathrm{a} 4 ; \mathrm{e}_{\mathrm{ijk}}=$ erro aleatório.

\section{Resultados e Discussão}

A ingestão e digestão ruminal da matéria seca não diferiram $(\mathrm{P}>0,05)$ entre as dietas avaliadas (Tabela 2$)$. A digestão intestinal e total de MS foi menor $(\mathrm{P}<0,05)$ na dieta que continha apenas monensina em comparação àquelas com probiótico. A digestibilidade aparente ruminal da matéria seca foi menor $(\mathrm{P}<0,05)$ na dieta com $50 \%$ da dose de cada aditivo. Os resultados da digestibilidade aparente intestinal e total da matéria seca comprovaram que as dietas contendo $5 \mathrm{~g} /$ dia de probiótico foram mais eficientes $(\mathrm{P}<0,05)$ que aquela contendo apenas o ionóforo (100I) com um adicional de $14 \%$ na digestibilidade total.

Zeoula et al. (2008) avaliando os efeitos da adição de Rumensin ${ }^{\circledR}$ e de probiótico, combinados ou não em dietas para bovinos e bubalinos, com diferentes níveis de concentrado, observaram valor médio para digestibilidade in vitro da MS (DIVMS) superior também na presença do probiótico (69\% para probiótico e 61\% para ionóforo) em dietas contendo 50\% de concentrado na MS. Esses autores afirmaram que a adição do produto contendo levedura teve efeito positivo na fermentação microbiana em todas as situações simuladas.

A ingestão da matéria orgânica não foi influenciada pelas dietas contendo ionóforo e/ou probiótico, porém as dietas influenciaram $(\mathrm{P}<0,05)$ a digestão ruminal da matéria orgânica, cujos maiores valores foram obtidos com as dietas com maior concentração de probiótico e para a dieta contendo $100 \%$ de ionóforo. A digestão intestinal da

Tabela 2 - Ingestão, digestão e coeficientes de digestibilidade aparente ruminal, intestinal e total da matéria seca, matéria orgânica e proteína bruta

\begin{tabular}{|c|c|c|c|c|c|}
\hline & \multicolumn{5}{|c|}{ Tratamentos $^{1}$} \\
\hline & $100 \mathrm{I}$ & $50 \mathrm{IP}$ & $100 \mathrm{IP}$ & $100 \mathrm{P}$ & $\mathrm{EPM}^{2}$ \\
\hline & \multicolumn{5}{|c|}{ Matéria seca } \\
\hline Digestão ruminal (g/dia) & 3108,43 & 2941,73 & 3250,42 & 3208,37 & 90,45 \\
\hline Digestão intestinal (g/dia) & $995,09 b$ & $1359,50 a$ & $1364,43 a$ & $1562,33 a$ & 76,82 \\
\hline Digestão total (g/dia) & $4103,52 b$ & $4301,23 a$ & $4614,85 a$ & $4770,70 \mathrm{a}$ & 96,30 \\
\hline Coeficiente de digestibilidade aparente ruminal (\%) & $48,61 \mathrm{a}$ & $46,47 \mathrm{~b}$ & $51,30 \mathrm{a}$ & $49,74 a$ & 0,67 \\
\hline Coeficiente de digestibilidade aparente total (\%) & \multicolumn{5}{|c|}{ Matéria orgânica } \\
\hline Ingestão (g/dia) & 6056,01 & 6050,24 & 6050,30 & 6090,80 & 10,35 \\
\hline Digestão ruminal (g/dia) & $2977,41 \mathrm{a}$ & $2779,36 b$ & $3050,00 \mathrm{a}$ & $2999,35 a$ & 23,42 \\
\hline Digestão intestinal (g/dia) & $948,50 c$ & $1342,38 b$ & $1360,00 \mathrm{~b}$ & $1539,94 a$ & 25,46 \\
\hline Digestão total (g/dia) & $3925,91 d$ & $4121,74 c$ & $4410,00 \mathrm{~b}$ & $4539,29 a$ & 11,27 \\
\hline Ingestão (g/dia) & 908,43 & 849,78 & 887,43 & 898,88 & 3,78 \\
\hline Digestão ruminal (g/dia) & $468,33 a$ & $404,18 b$ & $299,45 c$ & $245,55 d$ & 6,48 \\
\hline Digestão intestinal (g/dia) & $170,43 c$ & $174,87 \mathrm{c}$ & $284,48 b$ & $328,50 a$ & 3,25 \\
\hline Digestão total (g/dia) & $638,76 a$ & $579,05 b$ & $583,93 b$ & $574,05 b$ & 7,55 \\
\hline Coeficiente de digestibilidade aparente ruminal (\%) & $51,55 a$ & $47,56 b$ & $33,74 c$ & $27,32 d$ & 0,58 \\
\hline Coeficiente de digestibilidade aparente intestinal (\%) & $38,73 b$ & $39,24 b$ & $48,38 a$ & $50,28 a$ & 0,72 \\
\hline Coeficiente de digestibilidade aparente total (\%) & $70,31 \mathrm{a}$ & $68,14 \mathrm{ab}$ & $65,80 \mathrm{~b}$ & $63,86 b$ & 0,59 \\
\hline
\end{tabular}


MO, no entanto, foi maior $(\mathrm{P}<0,05)$ para a ração contendo apenas probiótico (100P) e menor para a dieta contendo apenas ionóforo (100I). A dieta 100P aumentou $(\mathrm{P}<0,05)$ a digestão total da matéria orgânica em $9 \%$ quando comparada à média das outras dietas. A menor digestibilidade ruminal de $\mathrm{MO}$ ocorreu $(\mathrm{P}<0,05)$ com a dieta que continha apenas $50 \%$ das doses dos dois aditivos. As digestibilidades intestinal e total da MO foram superiores para a dieta que continha apenas probiótico (100P). De acordo com Wiedmeier et al. (1987) e Gomez et al. (1990), a inclusão do probiótico melhora a digestibilidade da matéria orgânica, em decorrência do aumento significativo na digestibilidade da fibra, resultado de maior população bacteriana, maior estímulo à bactérias gram-negativas utilizadoras de ácido lático, além do estímulo à maior captação de oxigênio do meio ruminal.

A inclusão de ionóforo e probiótico, em diferentes dosagens nas dietas, não teve efeito $(\mathrm{P}>0,05)$ sobre a ingestão da proteína bruta. Os demais parâmetros analisados, ou seja, digestão ruminal, intestinal e total e os coeficientes de digestibilidade aparente, ruminal, intestinal e total da $\mathrm{PB}$ foram influenciados $(\mathrm{P}<0,05)$ pelas dietas.
A digestão da proteína no rúmen foi maior $(\mathrm{P}<0,05)$ para a dieta com 200 mg de monensina (100I) em relação às demais. A digestibilidade intestinal da proteína foi maior $(\mathrm{P}<0,05)$ para a dieta que continha apenas probiótico (100P), cujo valor foi 64,7 g/dia mais alto (Tabela 2) em comparação à dieta com apenas probiótico (100P). Da mesma forma, o coeficiente de digestibilidade aparente da proteína no rúmen foi maior para a dieta que continha apenas ionóforo (100I), cujo valor foi praticamente o dobro (51,55\%) do obtido com a dieta contendo apenas levedura $100 \mathrm{P}(27,32 \%)$.

A digestibilidade total da PB para a dieta 100I foi de 6,5 unidades percentuais superior à da dieta $100 \mathrm{P}$. Rodrigues et al. (2001), avaliando o efeito do ionóforo em dietas contendo diferentes proporções de volumoso e concentrado sobre a digestibilidade dos nutrientes em ovinos, observaram que a monensina também aumentou a digestibilidade da proteína bruta em 3,6 unidades percentuais, independentemente do nível de fibra na dieta.

As dietas não influenciaram $(\mathrm{P}>0,05)$ a ingestão, a digestão total e o coeficiente de digestibilidade aparente

Tabela 3 - Taxas de digestão e coeficientes de digestibilidade aparente ruminal, intestinal e total da fibra em detergente neutro, dos carboidratos não-fibrosos, extrato etéreo e nutrientes digestíveis totais

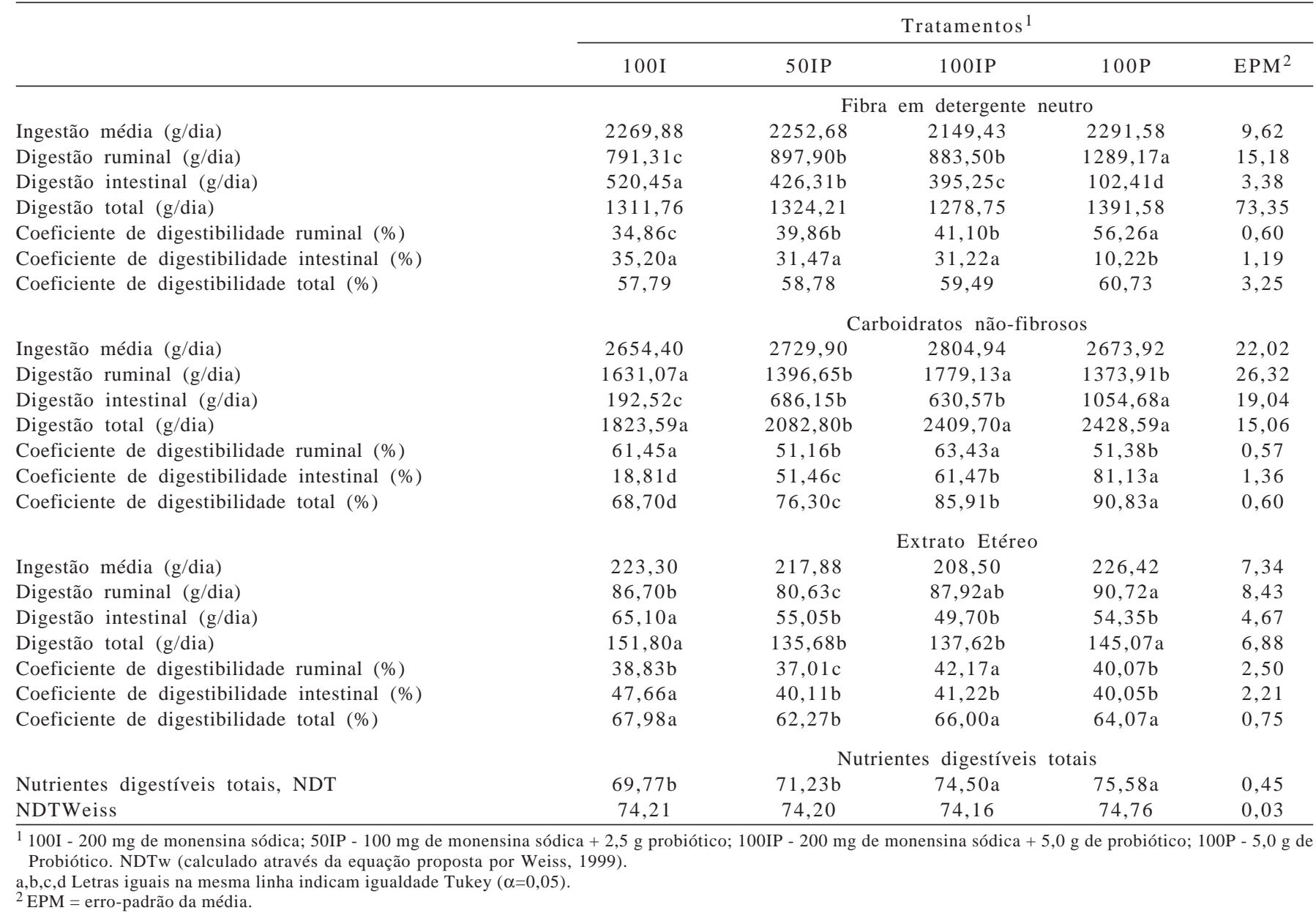


total da FDN (Tabela 3), mas a digestão e a digestibilidade ruminal da FDN foi maior $(\mathrm{P}<0,05)$ para a dieta com $100 \mathrm{P}$ (1289,23 g/dia) em relação à dieta 100I (791,28 g/dia), o que indica um ambiente ruminal mais adequado para microrganismos celulolíticos com o uso do probiótico.

Segundo Martin \& Nisbet (1992), no rúmen, os efeitos do probiótico são, de maneira geral, maior número de bactérias celulolíticas, o que melhoraria a digestão da parede celular, a produção de fatores de crescimento para os microrganismos do rúmen e o aumento do número de bactérias Selenomonas ruminantium na produção de propionato, acetato, succinato e do total de ácidos graxos voláteis no rúmen. Já o efeito dos ionóforos sobre a digestibilidade da fibra, segundo Spears (1990), parece depender da composição da dieta e da fonte da fibra, uma vez que, tanto o aumento como a diminuição da digestibilidade da fibra, têm sido associados à utilização de ionóforos.

As doses de monensina não influenciaram o consumo de carboidratos não-fibrosos, mas afetaram a digestão ruminal, intestinal e total $(\mathrm{P}<0,05)$ desses carboidratos. A inclusão do probiótico na dieta aumentou a digestão e a digestibilidade total dos carboidratos não-fibrosos.

O consumo de extrato etéreo foi semelhante entre as dietas ( $\mathrm{P}>0,05)$. A digestão ruminal, intestinal e total e os coeficientes de digestibilidade aparente ruminal, intestinal e total diferiram $(\mathrm{P}<0,05)$ entre as doses de monensina.

Os valores de NDT diferiram $(\mathrm{P}<0,05)$ entre as dietas. Os maiores valores foram obtidos com as dietas 100IP e 100P (74,50 e 75,58\%, respectivamente). No entanto, o NDT estimado pelos cálculos de Weiss (1999), não diferiram entre essas dietas. A maior concentração dos nutrientes digestíveis totais de 75,58\% para a dieta contendo a máxima dose de probiótico (100P) provavelmente foi reflexo da maior digestibilidade dos carboidratos não-fibrosos, porção mais prontamente disponível no rúmen, e garante aos microrganismos do rúmen a energia necessária para utilizar o nitrogênio disponível.

Os valores de $\mathrm{pH}$ do líquido ruminal dos bovinos submetidos às dietas com probiótico e/ou ionóforo não foram influenciados $(\mathrm{P}>0,05)$ pelas doses de monensina (Figura 1; Tabela 4).

McCarthy et al. (1989) observaram que a degradação ruminal da fibra foi prejudicada quando os valores de $\mathrm{pH}$ ruminal são inferiores a 6,20 , pois houve redução dos microrganismos celulolíticos. Os valores do $\mathrm{pH}$ do líquido ruminal em relação aos tempos e tratamentos variaram entre 6,00 e 6,73.

A concentração de amônia do líquido ruminal não foi influenciada $(\mathrm{P}>0,05)$ pelas dietas (Tabela 4). A maior concentração de amônia no rúmen foi de 38,74 mg/100 mL 2 horas após a alimentação e a concentração mínima foi de 4,63 mg/100 mL 8 horas após a alimentação (Figura 2). O valor mínimo de amônia no rúmen é muito próximo, porém abaixo, de $5 \mathrm{mg} / 100 \mathrm{~mL}$ de fluido ruminal referenciado por Sater \& Slyter (1974) como mínimo para manter a fermentação adequada da parede celular.

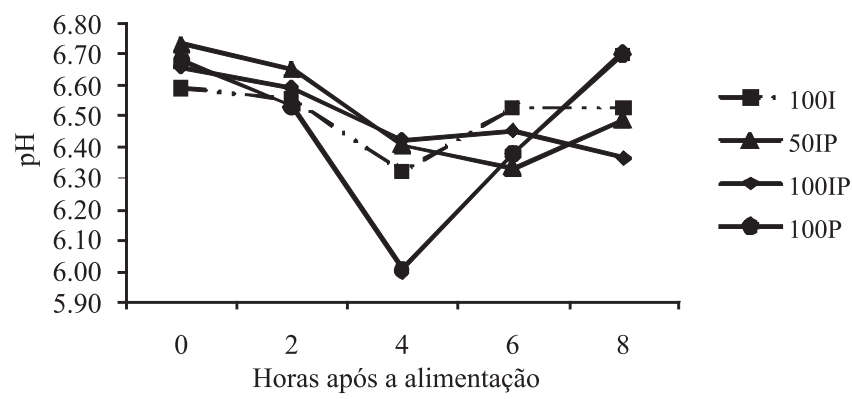

Figura 1 - pH ruminal após alimentação.

Tabela 4 - Ingestão média diária, fluxo omasal, digestão ruminal e coeficiente de digestibilidade aparente ruminal do nitrogênio, fluxo omasal de nitrogênio, eficiência microbiana aparente (EMA) e eficiência microbiana verdadeira

\begin{tabular}{|c|c|c|c|c|c|}
\hline & \multicolumn{5}{|c|}{ Tratamentos $^{1}$} \\
\hline & $100 \mathrm{I}$ & $50 \mathrm{IP}$ & $100 \mathrm{IP}$ & $100 \mathrm{P}$ & $\mathrm{EPM}^{2}$ \\
\hline $\mathrm{pH}$ ruminal & 6,50 & 6,52 & 6,50 & 6,46 & 0,03 \\
\hline $\mathrm{NH}_{3}$ ruminal $(\mathrm{mg} / \mathrm{dL})$ & 13,19 & 14,59 & 15,87 & 17,76 & 1,54 \\
\hline Ingestão (g/dia) & $145,35 a$ & $135,96 \mathrm{c}$ & $141,99 b$ & $143,82 \mathrm{ab}$ & 0,60 \\
\hline Fluxo omasal (g/dia) & $70,42 c$ & $71,30 \mathrm{c}$ & $94,08 b$ & $104,53 a$ & 0,52 \\
\hline Digestão ruminal (g/dia) & $74,93 a$ & $64,67 b$ & $47,91 \mathrm{c}$ & $39,29 d$ & 1,03 \\
\hline Coeficiente de digestibilidade aparente ruminal do nitrogênio (\%) & $51,55 a$ & $47,56 b$ & $33,74 \mathrm{c}$ & $27,32 d$ & 0,58 \\
\hline Fluxo omasal de nitrogênio bacteriano (g/dia) & $56,68 c$ & $56,06 \mathrm{c}$ & $76,14 b$ & $84,89 a$ & 0,42 \\
\hline Fluxo omasal de nitrogênio não-bacteriano (g/dia) & $13,73 d$ & $15,24 \mathrm{c}$ & $17,94 b$ & $19,64 a$ & 0,10 \\
\hline Eficiência microbiana aparente (g N/kg MODR) & $19,04 \mathrm{c}$ & $20,17 \mathrm{C}$ & $24,96 b$ & $28,30 \mathrm{a}$ & 0,41 \\
\hline Eficiência microbiana verdadeira (g N/kg MODR) & $15,01 b$ & $15,18 b$ & $17,73 \mathrm{a}$ & $19,29 a$ & 0,36 \\
\hline
\end{tabular}

1 100I - 200 mg de monensina sódica; 50IP - 100 mg de monensina sódica + 2,5 g probiótico; $100 \mathrm{IP}$ - 200 mg de monensina sódica + 5,0 g de probiótico; $100 \mathrm{P}$ - 5,0 g de Probiótico.

a,b,c,d Letras iguais na mesma linha, indicam igualdade, Tukey $(\alpha=0,05)$.

${ }^{2} \mathrm{EPM}=$ erro-padrão da média. 


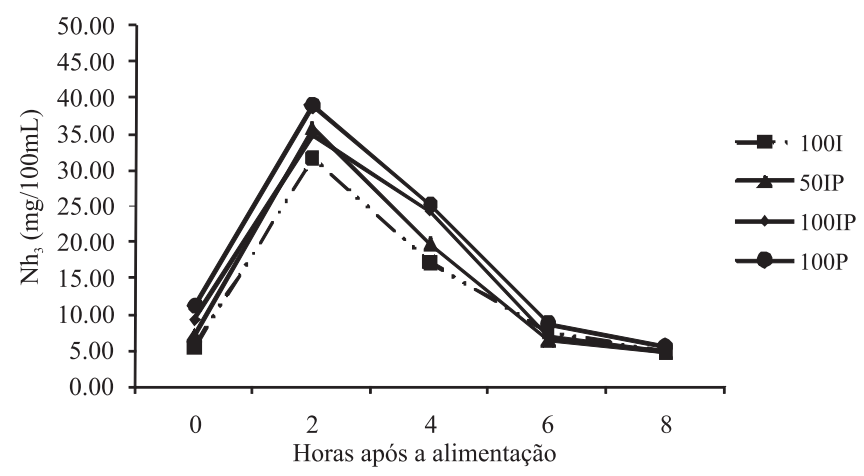

Figura 2 - Concentração de amônia ruminal após a alimentação.

Martin \& Nisbet (1992) observaram que a utilização de cultura de levedura na alimentação de vacas leiteiras eleva a concentração de amônia ruminal. Os autores afirmaram que a cultura de levedura pode potencializar a proteólise, provavelmente por fornecer nutrientes que estimulam as bactérias proteolíticas. O maior valor médio obtido para fluxo omasal de nitrogênio foi de 104,53 g/dia para a dieta contendo $100 \%$ de probiótico e sem monensina o qual foi superior $(\mathrm{P}<0,05)$ a todos os outros, evidenciando a maior passagem para o intestino do nitrogênio oriundo da dieta com 5 g de probiótico. O fluxo omasal obtidos com a dieta 100P foi superior em 34,11 g/dia, em decorrência da maior digestão ruminal da proteína bruta da dieta 100I e menor eficiência microbiana na síntese de proteína, chegando menos proteína proveniente do rúmen para o intestino delgado.

A eficiência de síntese microbiana aparente expressa em g N/kg de MODR (gramas de nitrogênio por kg de matéria orgânica degradada no rúmen) variou de 19,04 a 28,30 (dietas 100I e 100P, respectivamente), enquanto a eficiência microbiana verdadeira, também expressa em gN/kg de MODR, variou de 15,0 a 19,3. Murillo et al. (2002), trabalhando com touros Holandeses recebendo dietas com 50:50 (volumoso: concentrado) e suplementação com Saccharomyces cerevisiae, observaram aumento de eficiência microbiana ruminal em 11\% (20,9 × 23,3 g de $\mathrm{N}$-mic/MOFR) e quantidade de nitrogênio da dieta que chega ao duodeno em $8 \%(86,5 \times 93,8 \mathrm{~g}$ de $\mathrm{N} /$ dia $)(\mathrm{P}<0,05)$. Entretanto, não encontraram efeito na digestão ruminal de nitrogênio e na quantidade de $\mathrm{N}$-microbiano que chega ao duodeno, sugerindo que a suplementação de leveduras vivas pode aumentar a quantidade de nitrogênio sobrepassante. As diferenças entre a intensidade de resposta para os dois experimentos podem estar relacionadas ao tipo de dieta e à relação entre concentrado e volumoso, muito maior nesta pesquisa, confirmando que a resposta ao probiótico pode ser maior em dietas ricas em amido.
Não houve efeito $(\mathrm{P}>0,05)$ dos aditivos, ionóforo e/ou probiótico, sobre os teores de matéria seca (MS), matéria orgânica (MO) e nitrogênio (N) bacteriano (Tabela 5). Os valores de MS obtidos, que variaram, de 92,4\% a 94,6\% são semelhantes à média encontrada por Valadares Filho (1995), entre de 81,1 e $95,7 \%$.

Pereira et al. (2003), ao avaliarem a composição química dos microorganismos do rúmen de novilhos consumindo dietas à base de cana-de-açúcar suplementada com Saccharomyces cerevisiae mais ureia, encontraram valores médios da matéria seca microbiana $(91,0 \%)$ e do nitrogênio (5,24\%) semelhantes aos deste trabalho (94,6 e 5,25\%; respectivamente). O teor de nitrogênio microbiano observado variou de 5,25 a 6,17\% e situa-se na faixa de 5,2 a 8,7\% citada por Valadares Filho (1995) e na faixa de 5,0 a 12,4\% referenciada por Van Soest (1994).

Tabela 5 - Teores de matéria seca, matéria orgânica e nitrogênio das bactérias ruminais

\begin{tabular}{lccccc}
\hline & \multicolumn{5}{c}{ Tratamentos $^{1}$} \\
\cline { 2 - 6 } & $100 \mathrm{I}$ & $50 \mathrm{IP}$ & $100 \mathrm{IP}$ & $100 \mathrm{P}$ & EPM $^{2}$ \\
\hline Matéria seca (\%) & 94,03 & 92,43 & 92,72 & 94,61 & 0,76 \\
Matéria orgânica (\%) & 86,89 & 86,83 & 86,35 & 86,61 & 0,13 \\
Nitrogênio (\%) & 6,17 & 5,33 & 5,28 & 5,25 & 0,20 \\
\hline
\end{tabular}

1 100I = 100\% ionóforo; $50 \mathrm{IP}=50 \%$ ionóforo $+50 \%$ probiótico; $100 \mathrm{IP}=100 \%$ ionóforo $+100 \%$ probiótico; $100 \mathrm{P}=100 \%$ probiótico.

2 EPM = erro-padrão da média.

\section{Conclusões}

O uso de Saccharomyces cerevisiae em dietas com alta proporção de concentrado para bovinos aumenta a produção de massa microbiana e proporciona maior fluxo de proteína bacteriana disponível ao animal em comparação ao uso de monensina sódica, que aumenta a digestibilidade ruminal e total da proteína em comparação ao uso de Saccharomyces cerevisiae. A adição de Saccharomyces cerevisiae na dieta, associado ou não à monensina sódica, propicia aumento na digestão ruminal dos carboidratos da parede celular em bovinos em comparação à utilização de apenas ionóforo.

\section{Referências}

ASSOCIATION OF OFFICIAL ANALITICAL CHEMISTS - AOAC. Official methods of analysis. 15.ed. Arlington: AOAC International, 1990. 1422p.

BOHNERT, D.W.; LARSON, B.T.; BAUER, M.L. et al Nutritional evaluation of poultry byproduct meal as a protein source for ruminants: Effects on performance and nutrient flow and disappearance in steers. Journal of Animal Science, v.76, p.2474-2484, 1998. 
CECAVA, M.J.; MERCHEN, N.R.; GAY, L.C. et al. Composition of ruminal bacteria harvested from steers as influenced by dietary energy level, feeding frequency, and isolation techniques. Journal of Dairy Science, v.73, n.9, p.2480-2888, 1990.

COELHO DA SILVA, J.F.; LEÃO, M.I. Fundamentos de nutrição de ruminantes. Piracicaba: Livroceres, 1979. 380p.

GATTAS, C.B.A.; MORAIS, M.G.; ABREU, U.G.P. et al. Efeito da suplementação com cultura de levedura na fermentação ruminal de bovinos de corte. Revista Brasileira Zootecnia, v.37, n.4, p.711-716, 2008.

GOMEZ-ALARCON, R.A.; DUDAS, C.; HUBER, J.T. Influence of cultures of Aspergillus oryzue on rumen and total tract digestion of dietary components. Journal of Dairy Science, v.73, n.3, p.703-710, 1990.

KAMALAMMA, U.; KRISHNAMOORTY, U.; KRISHNAPPA, P. Effect of feeding yeast culture (Yea-sacc1026) on rumen fermentation in vitro and production performance in crossbred dairy cows. Animal Feed Science Technology, v.57, n.3, p.247-256, 1996.

LEAO, M.I.; VALADARES FILHO, S.C.; RENNÓ, L.N. et al. Consumos e digestibilidades totais e parciais de matéria seca, matéria orgânica, proteína bruta e extrato etéreo em novilhos submetidos a três níveis de ingestão e duas metodologias de coleta de digestas abomasal e omasal. Revista Brasileira de Zootecnia, v.33, n.6, p.1604-1615, 2004.

MARTIN, S.A.; NISBETI D.J. Effect of direct-fed microbials on rumen microbial fermentation. Journal of Dairy Science, v.75, p.1736-1744, 1992.

McCARTHY, R.D.; KLUSMEYER, J.R.; CLARK, T.H. et al. Effect of source of protein and carbohidrate on rumen fermentadion and passage of nutrients to the small intestine of lactating cows. Journal of Animal Science, v.62, p.216-225, 1989.

MURILLO, M.; VAZQUEZ, M.S.; QUINONES, A. et al. Effects of live yeast culture supplementation on nitrogen digestion and ruminal liquid kinectics in cattle. Journal of Dairy Science, v.85, p.359, 2002 (suppl. 1).

OLIVEIRA, M.V.M.; LANA, R.P.; JHAM, G.N. et al. Influência da monensina no consumo e na fermentação ruminal em bovinos recebendo dietas com teores baixo e alto de proteína. Revista Brasileira de Zootecnia, v.34, n.5, p.1763-1774, 2005.

PEREIRA, E.S.; QUEIROZ, A.C.; PAULINO, M.F. et al. Dinâmica dos nutrientes no trato gastrintestinal de novilhos Holandeses alimentados com dietas à base de cana-de-açúcar. Revista Brasileira de Zootecnia, v.32, n.6, p.1516-1524, 2003.

RODRIGUES, V.C.; ANDRADE, I.F.; SOUZA, J.C.D. Avaliação do consumo e da capacidade digestiva de búfalos e bovinos. Ciência Agrotécnica, v.25, p.1406-1412, 2001.

SALLES, M.S.V.; LUCCI, C.S. Monensina para bezerros ruminantes em crescimento acelerado. 2. Digestibilidade e parâmetros ruminais. Revista Brasileira de Zootecnia, v.29, n.2, p.582-588, 2000.
SATTER, L.D.; SLYTER, L.L. Effect of ammonia concentration on rumen microbial production in vitro. British Journal of Nutrition, v.32, n.2, p.199-208, 1974.

SNIFFEN, C.J.; O’CONNOR, J.D.; VAN SOEST, P.J. et al. A net carbohydrate and protein system for evaluating cattle diets: II. Carbohydrate and protein availability. Journal of Animal Science, v.70, n.11, p.3562-3577, 1992

SPEARS, W.J. Ionophores and nutrient digestion and absorption in ruminants. Journal of Nutrition, v.120, p.632-6385, 1990.

STATISTICAL ANALYSIS SYSTEM - SAS. SAS user's guide for windows environment 8.01. Cary: SAS Institute, 2001. $79 p$.

USHIDA, K.; LASSALAS, B.; JOUANY, J.P. Determination of assay parameters for RNA analysis in bacterial and duodenal samples by spectrophotometry. Influence of sample treatment and preservation. Reprodution Nutrition Developement, v. 25 , n.6, p.1037-1046, 1985

VALADARES FILHO, S.C. Eficiência de síntese de proteína microbiana, degradação ruminal e digestibilidade intestinal da proteína bruta, em bovinos. In: SIMPÓSIO INTERNACIONAL SOBRE EXIGÊNCIAS NUTRICIONAIS DE RUMINANTES. 1995, Viçosa, MG. Anais... Viçosa, MG: DZO/UFV, 1995. p.355-388.

VAN SOEST, P.J. Nutritional ecology of the ruminant. New York: Cornell University Press, 1994, 476p.

VAN SOEST, P.J.; ROBERTSON, J.B.; LEWIS, B.A. Methods for dietary fiber, neutral detergent fiber, and nonstarch polysaccharides in relation to animal nutrition. Journal of Dairy Science, v.74, p.3583-3597, 1991.

VIEIRA, P.F. Efeito do formaldeído na proteção de proteínas e lipídios em rações para ruminantes. 1980. 98f. Tese (Doutorado em Zootecnia) - Universidade Federal de Viçosa, Viçosa, MG

WALLACE, R.J. Ruminal microbiology, biotechnology, and ruminant nutrition: progress and problems. Journal of Animal Science, v.72, p.2992-3003, 1994.

WEISS, W. Energy prediction equations for ruminant feeds In:CORNELL NUTRITION CONFERENCE FOR FEED MANUFACTURERS, 61., 1999, Ithaca. Proceedings... Ithaca: Cornell University, 1999. p.176-185.

WIEDMEIER, R.D.; ARAMBEL, M.J.; WALTERS, J.L. Effect of yeast culture and Aspergillus oryzae fermentation extract on ruminal characteristics and nutrient digestibility. Journal of Dairy Science, v.70, p.2063-2068, 1987.

WILLIAMS, C.H.; DAVID, D.J. The determination chromic oxide in feces samples by atomic absorption spectrophotometry. Journal of Animal Science, v.59, n.1, p.391, 1962.

ZEOULA, L.M.; BELEZE, J.R.F.; GERON, L.J.V. et al. Digestibilidade parcial e total de rações com a inclusão de ionóforo ou probiótico para bubalinos e bovinos. Revista Brasileira de Zootecnia, v.37, n.3, p.563-571, 2008. 